\title{
Aspects of an Open Source Software Sustainable Life Cycle
}

\author{
Flávia Linhalis Arantes and Fernanda Maria Pereira Freire \\ Nucleus of Informatics Applied to Education (NIED) \\ State University of Campinas (UNICAMP) \\ Campinas, SP, Brazil \\ \{farantes, fernanda\}@unicamp.br
}

\begin{abstract}
In this paper we present a literature overview about OSS sustainability, considering not only financial resources, but also community growth, source code and tools management. Based on these aspects, we define an OSS life cycle that may contribute to OSS projects sustainability.
\end{abstract}

Keywords: OSS Sustainability, OSS Communities, Financial Resources, Software Maintenance

\section{Introduction}

With the popularity of OSS (Open Source Software), governments, universities and other institutions around the world are adopting free platforms aiming to save millions 112 .

A natural question that arises when one looks at the increasing use of such software for which you do not pay any fee or license is: how open source projects are supported?

Researches related to OSS sustainability 6914] show that the profits come from offering services such as support, consulting and training. In this work, we mean by sustainable the management model that can support the community through various resources. It is not, however, financially maintained by a single company or institution.

We present a study on other aspects, besides financial ones, that are also important for OSS projects sustainability. In the next sections we treat OSS projects sustainability broadly, considering the dynamics involved in a sustainable life cycle.

\section{An OSS Sustainable Life Cycle}

Based on a literature review, we can say that the sustainability of OSS is closely related to three factors - community growth, financial resources and software management, as illustrated in Figure 1. 
According to Figure 1, growth and continuity of the community can result more naturally in financial resources that, if well managed, can be reversed in benefits to the community and encourage its growth, feeding the OSS sustainable life cycle.

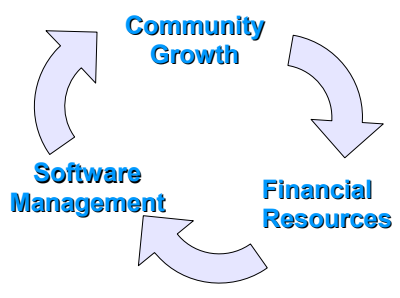

Fig. 1. Sustainable life cycle model for OSS projects.

The proper management of community, software and tools can decrease the financial resources necessary to maintain the project. With management improvements in that subjects, it is possible to minimize tasks and human factors, and to promote a vision of a robust computational development for the community. As a result, it is possible to reduce costs and, consequently, to contribute to the sustainability of OSS communities.

\subsection{Community Growth}

When we talk about OSS communities management, it is natural to think of reasons why communities continue to exist and to grow. Some important factors for the existence and continuity of an OSS community are: interactivity, variety of participants, large number of members, web space that allows interaction, matters of common interest, and cooperation among participants. A basic premise is that people should bring information and share it openly with the group. Another important attribute of a community is the population size. A community becomes more valuable as more members join it [18].

Researches also point out that community growth and development process openness can contribute to software quality and reliability [16 87]. This statement assumes that the more people are paying attention to the software and interacting with each other, the easier it is to find and to fix its bugs.

Researches also show that the continuity of an OSS community depends on the adoption of the software that it produces [18]. There are several factors for companies or individuals to take the decision to adopt certain free software. These factors include availability of support, size of community, technical attributes of software such as reliability, safety, quality and performance [115]. Software adoption can increase the visibility of the community and generate employment opportunities in bundled services (support, enhancements, upgrades) that can contribute to the community sustainability. 


\section{$2.2 \quad$ Financial Resources}

In most cases, OSS projects profits come from offering services such as support, consulting, training, product maintenance, and development of new software customizations 6 6/14. Free software can still be funded by various segments of society such as government, academia and corporations [34]. In order to receive more direct support from government, the groups associated with OSS often turn to NGOs, foundations and even micro companies 1814.

Many OSS economic aspects have been investigated in the literature. Riehle [13] tried to answer one of the main questions in the economic field of OSS projects: How is developers payment determined? Lerner and Tirole [10] discuss questions about economic justification of OSS projects. Shirali-Shahreza [15] discuss various OSS aspects, including economic ones.

\subsection{Software Management}

Factors related to source code structure can greatly contribute to OSS projects sustainability - it can lead to faster changes with less bugs. The code with a modular structure is an incentive for developers to enter and to continue in the project development 2]. Terceiro and colleagues [17] claim that structural complexity increases the cost of maintaining a software project, because the code becomes harder to understand, and consequently more difficult to modify. In OSS projects, this increased effort may represent an additional difficulty for the entry of new developers, and a sustainability problem.

The discontinuity of the development team and the geographically distributed nature of OSS projects make them even more difficult to manage. For issues like these, the need to communicate, interact and socialize using communication tools with computational support is even greater.

In order to coordinate their work, OSS communities members use the Internet with simple and widely available tools. There are two categories of tools used in OSS projects. The first one is related to communication between community members and the second concerns the management of source code.

A challenge to be exploited in this context is to investigate solutions on how to improve integration and communication between OSS tools, such as discussion forum, issue tracking, wiki, among others. The possibilities of using the communication that is made through these tools can reduce, for example, support costs and other activities that require time from the development team.

\section{Conclusion}

This study provided a brief overview, bringing together different aspects which contribute to OSS projects sustainability. With such a study we defined a sustainable life cycle aiming to provide guidance on the creation and maintenance of sustainable OSS development and communities. 


\section{References}

1. Allen, J.P.: Open source deployment at the city and county of san francisco: From cost reduction to rapid innovation. In: Hawaii International Conference on System Sciences, pp. 1-10 (2010)

2. Baldwin, C.Y., Clark, K.B.: The architecture of participation: Does code architecture mitigate free riding in the open source development model? Manage. Sci. 52, 1116-1127 (2006), http://portal.acm.org/citation.cfm?id=1246148.1246160

3. Capek, P.G., Frank, S.P., Gerdt, S., Shields, D.: A history of ibm's open-source involvement and strategy. IBM Syst. J. 44, 249-257 (2005), http://dx.doi.org/10.1147/sj.442.0249

4. Capra, E., Francalanci, C., Merlo, F., Rossi Lamastra, C.: A survey on firms participation in open source community projects. In: Boldyreff, C., Crowston, K., Lundell, B., Wasserman, A.I. (eds.) OSS 2009. IFIP AICT, vol. 299, pp. 225-236. Springer, Heidelberg (2009)

5. Dedrick, J., West, J.: An exploratory study into open source platform adoption. In: Proceedings of the Proceedings of the 37th Annual Hawaii International Conference on System Sciences (HICSS 2004) - Track 8, vol. 8, pp. 1-10. IEEE Computer Society, Washington, DC (2004), http://portal.acm.org/citation. cfm?id=962756.963252

6. Hecker, F.: Setting up shop: The business of open-source software. IEEE Softw. 16, 45-51 (1999), http://dx.doi.org/10.1109/52.744568

7. Joode, R.W., Bruijne, M.: The organization of open source communities: Towards a framework to analyze the relationship between openness and reliability. In: Hawaii International Conference on System Sciences, vol. 6, p. 118b (2006)

8. Lakhani, K., Wolf, R.G.: Why hackers do what they do: Understanding motivation and effort in free/open source software projects. Social Science Research Network, 1-27 (2003), http://www.ssrn.com/abstract=443040

9. Lawton, G.: The changing face of open source. Computer 42, 14-17 (2009)

10. Lerner, J., Tirole, J.: Some simple economics of open source. The Journal of Industrial Economics 50(2), 197-234 (2002), http://dx.doi.org/10.1111/1467-6451.00174

11. Morgan, L., Finnegan, P.: Benefits and drawbacks of open source software: An exploratory study of secondary software firms. In: Proceedings of the 3rd IFIP International Conference on Open Source Systems (OSS), pp. 307-312. Springer, Heidelberg (2007)

12. Richter, D., Zo, H., Maruschke, M.: A comparative analysis of open source software usage in germany, brazil, and india. In: Proceedings of the 2009 Fourth International Conference on Computer Sciences and Convergence Information Technology, ICCIT 2009, pp. 1403-1410. IEEE Computer Society, Washington, DC (2009), http://dx.doi.org/10.1109/ICCIT.2009.169

13. Riehle, D.: The economic motivation of open source software: Stakeholder perspectives. Computer 40, 25-32 (2007), http://portal.acm.org/citation.cfm?id=1251559.1251741

14. Riehle, D.: The economic case for open source foundations. Computer 43, 86-90 (2010)

15. Shirali-Shahreza, S., Shirali-Shahreza, M.: Various aspects of open source software development. In: International Symposium on Information Technology, ITSim 2008, vol. 4, pp. 1-7 (2008) 
16. Stamelos, I., Angelis, L., Oikonomou, A., Bleris, G.L.: Code quality analysis in open source software development. Inf. Syst. J. 12(1), 43-60 (2002)

17. Terceiro, A., Rios, L.R., Chavez, C.: An empirical study on the structural complexity introduced by core and peripheral developers in free software projects. In: Proceedings of the 2010 Brazilian Symposium on Software Engineering, SBES 2010, pp. 21-29. IEEE Computer Society, Washington, DC (2010), http://dx.doi.org/10.1109/SBES.2010.26

18. Vincentin, I.C.: Desenvolvimento de Software Livre no Brasil: estudo sobre a percepção dos envolvidos em relação às motivações ideológicas e de negócios. Ph.D. thesis, Faculdade de Economia, Administração e Contabilidade da Universidade de São Paulo (2007) 